\title{
Economic Efficiency of Maize Production in Swaziland: The Case of Hhohho, Manzini and Shiselweni Regions
}

\author{
M.B. Sihlongonyane ${ }^{1}$, M.B. Masuku ${ }^{2, *} \&$ A. Belete ${ }^{3}$ \\ ${ }^{1}$ P. O. Box 73, Hluti, Swaziland \\ ${ }^{2}$ Department of Agricultural Economics and Management, University of Swaziland, \\ Swaziland \\ ${ }^{3}$ Department of Agricultural Economics, University of Limpopo, South Africa \\ *Corresponding author: Department of Agricultural Economics and Management, P. O. \\ Luyengo, Luyengo, M205, University of Swaziland, Swaziland. Tel: 268-7602-6557. E-mail: \\ mbmasuku@uniswa.sz
}

Received: July 29, 2014 Accepted: August 27, 2014 Published: September 24, 2014

doi:10.5296/rae.v6i3.6045 URL: http://dx.doi.org/10.5296/rae.v6i3.6045

\begin{abstract}
The study used a sample of 188 maize farmers to determine the economic efficiency of maize production in Swaziland. Descriptive statistics, Cobb-Douglas production function and Tobit regression were used to analyse the data. The results indicated technical efficiency of $64.7 \%$ suggesting that farmers could still improve the technical efficiency by $35.3 \%$. While, allocative efficiency was $99.52 \%$, suggesting that farmers were able to use minimum costs to get a given level of output. In terms of economic efficiency, farmers were $64.3 \%$ efficient. They were able to use minimum inputs and at minimum costs for a given level of output. However, farmers could still increase their economic efficiency by 35.7\%. Technical Efficiency was affected by formal education $(p<0.01)$, and household size $(p<0.10$, while Allocative efficiency was affected by formal education $(p<0.10)$ and gender $(p<0.05)$. Economic efficiency was affected by household size $(\mathrm{p}<0.10)$. The study has shown that maize farmers were relatively economically efficient; hence the null hypotheses (1. Maize farmers are technically inefficient, 2 . Maize farmers are allocatively inefficient) were rejected in favour of the alternative. However famers can still improve economic efficiency by improving their technical efficiency. The study recommends that farmers should improve their technical efficiency by increasing productivity, and increasing amount of fertilizer applied per ha. There is a need for government to subsidize inputs for farmers and to continue with subsidizing the tractor hire services.
\end{abstract}

Keywords: Allocative efficiency, Cost function Approach, Economic Efficiency, Maize production, Technical efficiency 


\section{Introduction}

Maize is the staple food for the Swazi people and the most important crop grown in Swaziland. It is grown both on Swazi Nation Land (SNL) and Title Deed Land (TDL). The Swazi Nation Land is held in trust by traditional authorities for the Swazi people and about $90 \%$ of the crop is grown primarily under this system (Magagula et al., 2007). On SNL maize is often produced by smallholder farmers with no access to irrigation and production fluctuates depending on climatic conditions. SNL comprises of over 60 percent of the total arable land and less than $10 \%$ of total production on it is offered for sale. This has been the major drawback in the country's effort to be self-sufficient in maize production (West, 2000).

Maize yields on SNL are very low and are heavily dependent on rainfall. The average yield per ha on SNL is 4.42 tonnes of maize (Dlamini \& Masuku, 2011). Yields vary among the four agro-climatic zones in Swaziland, with the highest yields obtained in the Highveld and moist Middleveld (MOA, 2013). The land area under cultivation varies each season and so is the output. Maize farming on Swazi Nation Land is mainly to meet households' requirement with little intention for commercial purposes. The total area (SNL and TDL) under maize production is 9.33 hectares. Individual people or private companies own Title Deed Land (TDL). Thirty percent of Swaziland's population lives on TDL and most of the farms on TDL are large, modern and well equipped. They produce most of the agricultural produce that Swaziland exports (Magagula et al., 2007).The Title Deed Land covers an area of $40 \%$ of the total arable land in Swaziland (West, 2000). The average land holding is 4.9 hectares on TDL, while the average maize yield per ha is 9.75 tonnes (Dlamini \& Masuku, 2011).

The past 40 years has been particularly difficult years for maize producers in Swaziland, with domestic production consistently falling below consumption requirements of the population (NMC, 2012). In view of the lack of improved output per ha in maize production, a study was therefore conducted to determine how farmers use available resources and what can be done to maximize efficiency and thereby increase output in maize production. This study therefore sought to examine the economic efficiency of maize production by smallholder farmers in Swaziland.

The main objective of this study was to examine the economic efficiency of maize production in Swaziland. The specific objectives were to:

(i) Determine technical efficiency of maize production by smallholder farmers in Swaziland

(ii) Determine allocative efficiency of maize production

(iii)Identify factors affecting technical, allocative and economic efficiency of maize production 


\section{Theoretical framework}

Technical efficiency is defined by Farell (1957) as the ability of a firm to produce a given level of output with a given minimum quantity of input under certain technology. It is the ratio of the least possible amount of inputs, compared to the actual amount of inputs, used for producing a given amount of output. The ratio ranges between 0 and 1 , and the lower the ratio the lower the efficiency of the production process is (Ozkan, Ceylan \& Kizilay, 2009). According to Coelli (1996), thirty out of forty studies have used stochastic frontier production function on agricultural applications. This is mainly because the frontier production function introduces a disturbance term controlling statistical noise, measurement error and exogenous shocks which are beyond the control of the researcher (Russel \& Young, 1983). With regards to factors affecting technical efficiency, a study by Khan and Saeed (2011), found that education is key factor that influence technical efficiency as it sharpens managerial capabilities. It also found that old age is positively related to technical efficiency. On the other hand, a study by Essilfie (2011) observed that household size negatively influence technical efficiency as large population depletes limited available farmer's resources that could have been used to obtain inputs.

Allocative efficiency can be defined as the ratio of total cost of producing a unit of output to total cost of producing the same unit of output, while using optimal factor combinations in a technically efficient manner (Chukwuji et al., 2006). Allocative efficiency can be measured through cost efficiency, revenue efficiency and profit efficiency, which is a combination of the two (Wu, 1979). Cost efficiency is the ratio of respondents minimum possible production cost to actual production cost. Revenue efficiency is the ratio of the maximum possible income a respondent can receive to the actual income a respondent received. Profit efficiency is a combination of cost efficiency and revenue efficiency. Choice of the allocative efficiency measure depends on the characteristics of the market environment. Cost efficiency should be used to determine allocative efficiency when the price producers pay for inputs differ, while product prices are the same across the sample. For producers receiving different product prices, while facing the same input prices, revenue efficiency should be used as a measure of allocative efficiency. Profit efficiency can be used as a measure of allocative efficiency when input prices and product prices for producers differ (Merwe, 2012). Among the factors affecting allocative efficiency, Chiona (2011) noted that education; household composition and tillage systems affect allocative efficiency. Education increases managerial skills, while, large proportion of inactive members reduces labour availability and the use of conservational method in land preparation increases efficiency.

Farrell (1957) defined economic efficiency as the capacity of a firm to produce a predetermined quantity of output at the minimum possible cost for a given level of technology. Any deviation from the frontier or expansion path indicates economic inefficiency. Economic efficiency combines both allocative and technical efficiency. It is achieved when the producer combines resources in the least cost combination to generate maximum output (technical) as well as ensuring least cost to obtain maximum revenue (Chukwuji, et al., 2006). Two major approaches to measure and estimate efficiency exists (Okoye et al., 2006). The parametric approach, non-parametric approach. The parametric 
approach relies on econometric techniques while the non-parametric approach uses mathematical programming techniques (Sarafidis, 2002). The most popular under the parametric and non-parametric approaches used in efficiency analysis is the Stochastic Frontier Analysis (SFA) production function approach and the Data Envelopment Analysis (DEA), respectively (Speelman et al., 2008).

\section{Methodology}

\subsection{The Study area}

The focus of the study was on three administrative regions of Swaziland; Manzini, Hhohho and the Shiselweni region. According to FANRPAN (2003) these are the regions that produce $96 \%$ of the maize produced in the country. The Lubombo region produces only $4 \%$ of the total maize produced locally, hence the exclusion of the region. Within these regions there are depots, which are used by National Maize Corporation (NMC) to receive maize from farmers.

\subsection{Sampling procedure}

To control sample frame error, an up to date list of 539 farmers who were supplying NMC was obtained from NMC. This formed a sample frame. The sampling technique used in the study was a multi-stage sampling technique. The first stage involved purposive selection of maize farmers who supplied NMC in 2012/2013 in the four depots: Matsapha, Ngwemphisi, Madulini and Ntfonjeni. The use of purposive sampling in this study was to get those farmers who produced for both consumption and for selling. The second stage of the technique involved snowball sampling. One farmer who supplied NMC in 2012/2013 was identified in each depot; the farmer was then used to identify the others who were unknown to the interviewer. A sample of 188 farmers was selected following Roberts-Lombard (2006) formula of calculating sample size.

$$
n=\frac{N}{\left(1+N(e)^{2}\right)}
$$

Where:

$\mathrm{n}=$ the sample size, $\mathrm{N}=$ total population of farmers who supplied NMC in the three depots in 2012, e= margin of error. In light of this and with a confidence level of $90 \%$ and a margin of error of $10 \%$, 188 farmers were selected (Table 1).

Table 1. Sample size per region

\begin{tabular}{lcc}
\hline Region & Target population $(\mathrm{N})$ & Sample size $(\mathrm{n})$ \\
\hline Hhohho & 118 & 54 \\
Manzini & 250 & 71 \\
Shiselweni & 171 & 63 \\
Total & $\mathbf{5 3 9}$ & $\mathbf{1 8 8}$ \\
\hline
\end{tabular}

Source: National Maize Corporation, (2013) 


\subsection{Data collection procedure}

The study used primary data. The data were collected using a structured questionnaire. Four enumerators were used to collect the data. The enumerators were trained beforehand by the researcher. The training was done to help to avoid misunderstanding of the questionnaires as well as biasedness of data as a result of too much influence from interviewers to answer in a certain way.

\subsection{Data analysis}

Descriptive statistics involving means and percentages, A Cobb Douglas regression analysis and Tobit regression were used to analyse the data. The data were analysed using STATA 12.0 software. Economic efficiency was calculated as the product of technical and allocative efficiency, while Tobit regression model was used to determine factors affecting technical, allocative and economic efficiency.

\subsection{Analytical framework}

The estimation of frontier function and efficiency was completed in two stages. In the first-stage, a Cobb-Douglas stochastic frontier production function was estimated. The total output per ha was modeled in terms of five input variables, namely, amount of fertilizer, amount of human labour, quantity of seeds, amount of pesticides and farm size (all on a per ha basis). In the second-stage of the analysis, the estimated technicall efficiencies were regressed on various farm and farmer-specific variables, which were considered appropriate in explaining variations in economic efficiencies for the sampled farmers. The production function was represented as;

$$
Y=F(X \beta) \exp ^{E}
$$

Where $\mathrm{Y}=$ Maize outputs (kg/ha)

$$
\begin{aligned}
& X=\text { Vector of input quantities } \\
& \beta=\text { a vector parameters } \\
& E=\text { Stochastic disturbance term consisting of element } U \text { and } V, E=V-U
\end{aligned}
$$

The $\mathrm{V}$ is distributed randomly and a symmetrical two-sided error-term as $\mathrm{V} \sim \mathrm{N}\left(0, \mathrm{~s}_{\mathrm{v}}{ }^{2}\right)$, which captures the effects of random shocks outside the farmers control, i.e. observation and measurement error, and other statistical noise. Thus, V allows the frontier to vary across farms, or over time for the same farm, and therefore the frontier is stochastic.

The $\mathrm{U}$ is distributed half-normal one-sided error-term as $\mathrm{U} \sim \mathrm{N}\left(0, \mathrm{~s}_{\mathrm{u}}{ }^{2}\right)$ that captures deviations from the frontier due to inequality. Both $U$ and $V$ are independent of each other. The technical efficiency of an individual farm is defined as the ratio of the observed output to the corresponding frontier output, conditional on the levels of inputs used on farm.

$$
Y_{i}=\beta_{0} X_{1}^{\beta_{1}} X_{2}^{\beta_{2}} X_{3}^{\beta_{3}} X_{4}^{\beta_{4}} X_{5}^{\beta_{5}} u
$$




$$
\ln Y_{i}=\beta_{1} \ln X_{1_{i}}+\beta_{2} \ln X_{2_{i}}+\beta_{3} \ln X_{3_{i}}+\beta_{4} \ln X_{4_{i}}+\beta_{5} \ln X_{5_{i}}+U
$$

$\mathrm{i}=1,2, \quad \mathrm{n}^{\text {th }}$ farmer

Where,

$\ln =$ logarithm to base $\mathrm{e}$

$\mathrm{Y}_{\mathrm{i}}=$ Yield of maize in the $i^{\text {th }}$ farmer $(\mathrm{kg} / \mathrm{ha})$

$\mathrm{X}_{1}=$ Farm size (ha)

$\mathrm{X}_{2}=$ Quantity of fertilizer used in maize crop $(\mathrm{kg} / \mathrm{ha})$

$\mathrm{X}_{3}=$ Amount of seeds used $(\mathrm{kg} / \mathrm{ha})$

$\mathrm{X}_{4}=$ Amount of pesticides (litres)

$\mathrm{X}_{5}=$ Total labour used in maize crop (man-hours/ ha)

$\mathrm{U}=$ Random error-term $(\mathrm{V}-\mathrm{U})$

$\mathrm{n}$ = sample size

Technical efficiency indices were regressed on farm and farmer characteristics to determine the factors affecting technical efficiency using a Tobit regression model. The model was specified as follows:

$$
\begin{gathered}
Y^{*}=\mathrm{X} B_{i}+\varepsilon_{i} \\
Y_{i}^{*}=\alpha_{0+} \alpha_{1} P_{1 i}+\alpha_{2} P_{2 i}+\alpha_{3} P_{3 i}+\alpha_{4} P_{4 i}+\alpha_{5} P_{5 i}+\alpha_{6} P_{6 i}+\alpha_{7} P_{7 i}+\alpha_{8} P_{8 i}+\alpha_{9} P_{9 i}
\end{gathered}
$$

Where $\mathrm{Y}^{*}=$ Technical efficiency ratio

$\mathrm{P}_{1}=$ Farmers age (in years)

$\mathrm{P}_{2}=$ Years of farming experience

$\mathrm{P}_{3}=$ Years of formal education

$\mathrm{P}_{4}=$ Gender (female $=0$, male $=1$ )

$\mathrm{P}_{5}=$ Household size (number)

$\mathrm{P}_{6}=$ Off-farm income (no $=0$, yes $=1$ )

$\mathrm{P}_{7}=$ Major occupation (part-time farmer $=0$, full-time farmer $=1$ )

$\mathrm{P}_{8}=$ Cropping system $($ monocropping $=0$, intercropping $=1$, both $=2$ )

$\mathrm{P}_{9}=$ Seed type (hybrid $=0$, non-hybrid $=1$, both $=2$ )

Allocative efficiency was attained using the cost function. The study assumed that total cost was dependent on cost of inputs. The total cost of inputs was regressed on each of the 


\section{Macrothink}

Research in Applied Economics

ISSN 1948-5433

2014, Vol. 6, No. 3

independent variables to determine the extent of the relationship that exist between the dependent and the independent variables.

Thus, the specific model estimated is given by

$$
\begin{gathered}
Y=A X_{1}^{\alpha_{1}} X_{2}^{\alpha_{2}} X_{3}^{\alpha_{3}} X_{4}^{\alpha_{4}} X_{5}^{\alpha_{5}} v \\
=\alpha_{o}+\alpha_{1} X_{1_{i}}+\alpha_{2} X_{2_{i}}+\alpha_{3} X_{3_{i}}+\alpha_{4} X_{4_{i}}+\alpha_{5} X_{5_{i}}+v
\end{gathered}
$$

Where

$\mathrm{Y}=$ Total costs $(\mathrm{E} / \mathrm{ha})$

$\mathrm{X}_{1}=$ Yield (kg/ha)

$\mathrm{X}_{2}=$ Cost of human labour used (E/ha)

$\mathrm{X}_{3}=$ Cost of fertiliser used (E/ha)

$\mathrm{X}_{4}=$ Tractor costs $(\mathrm{E} / \mathrm{ha})$

$\mathrm{X}_{5}=$ Cost of seeds $(\mathrm{E} / \mathrm{ha})$

$\mathrm{X}_{6}=$ Cost of pesticide (litres)

$\mathrm{A}=$ Constant

$\mathrm{v}=$ Random error term $(\mathrm{V}+\mathrm{U})$

The efficiency scores were regressed on farmer and farm characteristics using a Tobit regression model as shown in equation 9. It was assumed that allocative efficiency effects were independently distributed and $\mathrm{Y}_{\mathrm{i}}{ }^{*}$ arise by truncation at zero of the normal distribution.

$$
\begin{gathered}
Y=A Z_{1}{ }^{\alpha_{1}} Z_{2}{ }^{\alpha_{2}} \ldots Z_{n}{ }^{\alpha_{n}} v \\
Y_{i}^{*}=\alpha_{0+} \alpha_{1} Z_{1 i}+\alpha_{2} Z_{2 i}+\alpha_{3} Z_{3 i}+\alpha_{4} Z_{4 i}+\alpha_{5} Z_{5 i}+\alpha_{6} Z_{6 i}+\alpha_{7} Z_{7 i}+\alpha_{8} Z_{8 i}+\alpha_{9} Z_{9 i}
\end{gathered}
$$

Where $\mathrm{Y}^{*}=$ Allocative efficiency ratio

$\mathrm{Z}_{1}=$ Farmers age (years)

$\mathrm{Z}_{2}=$ Years of farming experience

$\mathrm{Z}_{3}=$ Years of formal education

$\mathrm{Z}_{4}=$ Gender $($ female $=0$, male $=1$ )

$\mathrm{Z}_{5}=$ Household size (persons)

$\mathrm{Z}_{6}=$ Off-farm income $($ no $=0$, yes $=1)$

$\mathrm{Z}_{7}=$ Major occupation (part-time farmer $=0$, full-time farmer $=1$ )

$\mathrm{Z}_{8}=$ Cropping system (monocropping $=0$, intercropping $=1$, both $=2$ ) 
$\mathrm{Z}_{9}=$ Seed type (hybrid $=0$, non-hybrid $=1$, both $=2$ )

According to Bravo-ureta and Pinheiro (1997) economic efficiency is the product of technical efficiency and allocative efficiency. The economic efficiency of each farmer was calculated as the product of allocative efficiency and technical efficiency. The model specification for economic efficiency is as shown in equation 11.

$$
\mathrm{EE}_{i}=\mathrm{AE}_{i} \times \mathrm{TE}_{i}
$$

Where

$\mathrm{i}=1,2, \ldots, \mathrm{n}^{\text {th }}$ farmer

$\mathrm{EE}=$ Economic efficiency

$\mathrm{AE}=$ Allocative efficiency

$\mathrm{TE}=$ Technical efficiency

In measuring the factors affecting economic efficiency levels, a Tobit regression model was used. The estimated efficiency scores were regressed on a set of socio-economic factors that were assumed to be important determinants of efficiency. The Tobit regression model was considered more appropriate since the values of the dependent variable (efficiency scores) lied within a certain interval $(0$ - 1). It was assumed that efficiency effects were independently distributed and Uij arises by truncation (at zero) of the normal distribution with mean $U i j$ and variance $\sigma^{2}$, such that

$$
U_{i}^{*}=\beta_{0}+\beta_{1} X_{1 i}+\beta_{2} X_{2 i}+\ldots \beta_{n} X_{n i}
$$

Where $i=1,2,3 \ldots \mathrm{n}^{\text {th }}$ farmer

$\mathrm{U}^{*}=$ Economic efficiency ratio

$\mathrm{X}_{1}=$ Farmers age (years)

$\mathrm{X}_{2}=$ Years of farming experience (years)

$\mathrm{X}_{3}=$ Years of formal education (years)

$\mathrm{X}_{4}=$ Gender $($ female $=0$, male $=1)$

$\mathrm{X}_{5}=$ Household size (persons)

$\mathrm{X}_{6}=$ Off-farm income $($ no $=0$, yes $=1)$

$\mathrm{X}_{7}=$ Major occupation (part-time farmer $=0$, full-time farmer $=1$ )

$\mathrm{X}_{8}=$ Cropping system (monocropping $=0$, intercropping $=1$, both $=2$ )

$\mathrm{X}_{9}=$ Seed type (hybrid $=0$, non-hybrid $=1$, both $=2$ )

The $\mathrm{U}^{*}$ was calculated as the product of $\mathrm{AE}$ and TE. Regression diagnostics was done for the 
models to ensure that the available data meets the assumption of OLS regression. Firstly the linearity assumption was checked to see if the relationships between the variables and the outcome variable were linear. The data were also tested for multicollinearity and there was none.

\section{Results and discussion}

\subsection{Description of study sample}

A sample of 188 farmers was taken from a population of 539 famers in the Manzini, Hhohho and Shiselweni region. In the Manzini region 71 farmers were selected, 54 farmers in the Hhohho region and 63 farmers in the Shiselweni region. Table 2 is a descriptive statistics of the variables used in the study. Farming experience is no doubt one of the strong points of local maize farmers. The average farming experience was 27 years and the minimum and maximum experience possessed by farmers was 3 and 50 years respectively. The average household size was 9 persons, the minimum was 2 persons and the maximum was 20 persons. On average farmers used $210.5 \mathrm{~kg}$ of fertilizer per ha, the minimum was $65 \mathrm{~kg}$ and the maximum was $475 \mathrm{~kg}$. On the other hand, farmers used an average of $15.39 \mathrm{~kg}$ of seeds per ha. The minimum and maximum was $5 \mathrm{~kg}$ and $32.5 \mathrm{~kg}$ per ha respectively.

Table 2. Descriptive statistics for variables used in the study

\begin{tabular}{lrrr}
\hline Variable & Mean & Minimum & Maximum \\
\hline Output (kg/ha) & 1254.49 & 166.67 & 4900 \\
Age (years) & 58 & 24 & 82 \\
Formal education (years) & 7 & 0 & 16 \\
Farmers' experience (years) & 27 & 3 & 50 \\
Household size (persons) & 9 & 2 & 20 \\
Fertilizer amount (kg) & 4.21 & 0.64 & 9.5 \\
Amount of seeds (kg) & 15.39 & 5 & 32.5 \\
Amount of pesticide (litres) & 0.77 & 0.17 & 3.33 \\
Amount of labour (man-hrs) & 345.38 & 26.2 & 1761 \\
Farm size (ha) & 3 & 1 & 6 \\
pesticide costs (E) & 65.9 & 6.25 & 375 \\
Hired labour costs (E) & 1061.71 & 20 & 5900 \\
Tractor costs (E) & 661.57 & 106.67 & 1680 \\
Fertilizer costs (E) & 1271.7 & 160 & 4916.67 \\
Seed costs (E) & 394.52 & 60 & 1700 \\
Total costs (E) & 1656 & 258.71 & 7315 \\
\hline
\end{tabular}

Table 3 shows that out of 188 farmers interviewed, 70 farmers were females and 118 farmers were males. A large proportion of farmers had no other income as only 75 persons agreed to have had other sources of income while 113 persons only relied on maize production as a source of income. This was also explained by the fact that $61.2 \%$ of farmers were on full time farming while $38.8 \%$ were on part time basis. Those on part time basis were able to use 
resources from other income to get inputs.

Intercropping has the potential of enriching the soil with other nutrients that are not easily available in the soil. It also provides soil cover and improves infiltration. However, only $2.1 \%$ of farmers practiced intercropping and $87.8 \%$ only used monocropping, while $10.1 \%$ used both monocropping and intercropping. Most farmers in the study area used hybrid seeds as 137 of them were recorded to have used it. Only 14 farmers used non hybrid and 37 used both hybrid and non-hybrid.

Table 3. Farmer and farm characteristics

\begin{tabular}{lcr}
\hline Dummy variables & Frequency & Percentage \\
\hline Gender & 70 & 37.2 \\
Female & 118 & 62.8 \\
Male & & \\
Other income & 113 & 60.1 \\
No & 75 & 39.9 \\
Yes & & \\
Occupation & 73 & 38.8 \\
Part-time farmer & 115 & 61.2 \\
Full-time farmer & & \\
Cropping systems & 165 & 87.8 \\
Monocropping & 4 & 2.1 \\
Intercropping & 19 & 10.1 \\
Both & & \\
Seed type & 137 & 72.9 \\
Hybrid & 14 & 7.4 \\
Non hybrid & 37 & 19.7 \\
Both & &
\end{tabular}

Table 4 presents the distribution of yield in the study areas. The maximum yield obtained per ha from the study was $4900 \mathrm{~kg}$ and the average yield was $1254 \mathrm{~kg}$ per ha. It has been noted through the National Maize Competition (NAMCOM) that farmers on Swazi Nation Land (SNL) can produce up to $14200 \mathrm{~kg}$ per ha of maize locally. The average recommended yield of maize on SNL is 3000 to $5000 \mathrm{~kg}$ per ha. The results of the study indicate that farmers had a poor harvest in the season 2012/2013. Table 4 shows that the Hhohho region produced better yield followed by Shiselweni and Manzini region respectively. This could be because the Hhohho region is mostly in the Highveld, which has high rainfall. The average yield for maize farmers in the Hhohho region was 1.558 tonnes per ha and the maximum was $4900 \mathrm{~kg}$ per ha, while the Shiselweni region had an average of $1210 \mathrm{~kg}$ per ha and the maximum yield was $4200 \mathrm{~kg}$ per ha, lastly, the Manzini region followed with an average of $1061 \mathrm{~kg}$ per ha and recorded a maximum yield of $2750 \mathrm{~kg}$ per ha. 
Table 4. Distribution of yield in the study area

\begin{tabular}{llll}
\hline Region & Average yield per ha $(\mathrm{kg})$ & Minimun(kg) & Maximum $(\mathrm{kg})$ \\
\hline Hhohho & 1558.93 & 250 & 4900 \\
Manzini & 1061.57 & 166.7 & 2750 \\
Shiselweni & 1210.94 & 250 & 4200 \\
\hline
\end{tabular}

\subsection{Technical efficiency analysis}

Table 5 indicates that only farm size and the amount of fertilizer were significant. Both were significant at $1 \%$ level. Contrary to expectation, farm size was negatively related to technical efficiency. This suggests that as farm size increases the level of technical efficiency is reduced. A $1 \%$ increase in farm size would decrease output by $0.29 \%$. These findings are in line with Frisvold and Ingram (1994) who found that for small fields the production is normally small, but in terms of productivity or production per hectare they perform better than larger plots.

In as far as the use of fertilizer is concerned, a 1\% increase in the amount of fertilizer used would increase maize yield by $0.23 \%$. The findings were as expected since fertilizer supply plants with important nutrients. There is a limit however, that the amount of fertilizer should not exceed for maximum recommended amount.

The technical efficiency of maize farmers was $64.7 \%$. That means that farmers can still increase inputs to increase yield by $35.3 \%$. The minimum efficiency score was $19.8 \%$, while the maximum obtained was $92.1 \%$. The variation is huge and this could be due to the differences in agro-climatic conditions between the three regions. Despite the high proportion of farmers with EE above average, therefore there is still room to improve technical efficiency.

Table 5. Parameter estimates of the stochastic production function

\begin{tabular}{lccc}
\hline Independent variable & Coef & t- value & P- value \\
\hline lnFarm size (ha) & $-0.2918^{*}$ & -3.25 & 0.003 \\
lnFertilizer (kg) & $0.2306^{*}$ & 3.67 & 0.000 \\
lnSeeds (kg) & 0.0596 & 0.66 & 0.510 \\
lnPesticide (litres) & 0.0302 & 0.44 & 0.658 \\
lnLabour (man-hours) & 0.0561 & 1.07 & 0.286 \\
Constant & 6.9921 & 17.52 & 0.000 \\
\hline
\end{tabular}

* Significant at $1 \%$ level

According to Table 6 the Hhohho region had a high technically efficiency compared to the other regions. It recorded $71.3 \%$, followed by Shiselweni with $62.5 \%$ and then Manzini region with 61.6\%. Both Shiselweni and Manzini regions have their averages below the average for the study sample. The proportion of Manzini region in the whole sample and the lack of other off-farm income to buy inputs could be the reason of low average technical efficiency. Likewise, with Shiselweni region, lack of other income could have caused under-utilization of inputs as it was the case with pesticides 
Table 6. Regional Technical efficiency scores

\begin{tabular}{llll}
\hline Region & Average (\%) & Minimum(\%) & Maximum(\%) \\
\hline Hhohho & 71.3 & 27.2 & 92.1 \\
Manzini & 61.6 & 19.8 & 89.3 \\
Shiselweni & 62.5 & 24 & 87.7 \\
\hline
\end{tabular}

\subsection{Allocative efficiency analysis}

The cost function results in Table 7 were used to generate allocative efficiency indices. All the variable input costs were statistically significant at $1 \%$ level except tractor costs. Pesticide cost has been omitted as a result of collinearity. A $1 \%$ increase in labour costs increases total costs by $0.20 \%$. A $1 \%$ increase in fertilizer costs would increase total costs by $0.27 \%$. While a $1 \%$ increase in seed costs would increase total costs by $0.33 \%$.

The average allocative efficiency of maize farmers in Swaziland was 99.52\%. This means farmers were able to operate profitably as they were able to produce a reasonable level of output using minimum costs. The maximum allocative efficiency score was $99.53 \%$ and the minimum was $99.50 \%$.

Table 7. Coefficient estimates of the cost function

\begin{tabular}{lllll}
\hline Independent variable & Coef. & Std. Err & t-value & P-value \\
\hline InLabour costs & $0.1977^{*}$ & 0.0730 & 2.71 & 0.007 \\
ln Fertilizer costs & $0.2680^{*}$ & 0.0791 & 3.39 & 0.001 \\
ln Tractor costs & 0.1287 & 0.0929 & 1.39 & 0.168 \\
ln SeedCost & $0.3328^{*}$ & 0.0953 & 3.49 & 0.001 \\
Constant & 0.9081 & 0.8208 & 1.11 & 0.270 \\
\hline
\end{tabular}

* Significant at $1 \%$ level

\subsection{Economic efficiency analysis}

Economic efficiency was calculated as the product of technical efficiency and allocative efficiency. Farell (1957) defined economic efficiency as the ability of a farmer to produce a predetermined quantity of output at minimum possible cost for a given level of technology. Table 8 is a summary of technical, allocative and economic efficiency frequency distribution. Only $1 \%$ of the farmers recorded a technical efficiency of more than $90 \%$ and none got less than 10\%. Most farmers (31\%) got a technical efficiency between 70 and $80 \%$. All the farmers were allocatively efficient as none got a score of less than $99.3 \%$. One percent of farmers were between $90 \%$ and $100 \%$ economically efficient in producing maize, while $15 \%$ of farmers were $80 \%$ and above. A majority of the farmers (30\%) were between 70 and $80 \%$. There were only $1 \%$ of farmers who were less than $20 \%$. Considering the difference between the maximum economic efficiency achieved and the minimum, which is $91.6 \%$ and $19.7 \%$ respectively, there is still a lot of improvement that farmers need to do. 
Table 8. Summary of frequency distribution of TE, AE, and EE

\begin{tabular}{cccccccc}
\hline Efficiency range & \multicolumn{2}{c}{ Technical efficiency } & \multicolumn{2}{c}{ Allocative efficiency } & \multicolumn{2}{c}{ Economic efficiency } \\
\cline { 2 - 7 } & Frequency & $\%$ & Frequency & $\%$ & Frequency & $\%$ \\
\hline $90-100$ & 2 & 1 & 188 & 100 & 2 & 1 \\
$80-89.99$ & 30 & 16 & 0 & 0 & 28 & 15 \\
$70-79.99$ & 58 & 31 & 0 & 0 & 57 & 30 \\
$60-69.99$ & 35 & 19 & 0 & 0 & 37 & 20 \\
$50-59.99$ & 23 & 12 & 0 & 0 & 22 & 12 \\
$40-49.99$ & 20 & 11 & 0 & 0 & 20 & 11 \\
$30-39.99$ & 11 & 6 & 0 & 0 & 12 & 6 \\
$20-29.99$ & 8 & 4 & 0 & 0 & 9 & 5 \\
$10-19.99$ & 1 & 1 & 0 & 0 & 1 & 1 \\
\hline \multicolumn{1}{c}{ Total } & 188 & 100 & 188 & 100 & 188 & 100 \\
\hline Average & 64.7 & & 99.4 & & 64.3 & \\
Maximum & 92.10 & & 99.4 & & 91.6 & \\
Minimum & 19.80 & & 99.3 & & 19.7 & \\
\hline
\end{tabular}

Table 9 shows the regional economic efficiency of farmers. Farmers in the Hhohho region scored better even in this analysis. The average economic efficiency in the Hhohho region was $70.9 \%$, 8.9\% more than the second, which was Shiselweni, who got $62.2 \%$. Manzini region was the least with $61.3 \%$. The difference could be caused by the difference in agro-climatic conditions as they favour Hhohho and part of Shiselweni region. The maximum economic efficiency per individual farmer was also high in the Hhohho region, followed by Manzini and Shiselweni with economic efficiency scores of 91.5, 88.8 and $87.2 \%$ respectively

Table 9. Comparison economic efficiency by regions

\begin{tabular}{lccc}
\hline Region & $\begin{array}{c}\text { Economic efficiency } \\
\text { mean (\%) }\end{array}$ & $\begin{array}{c}\text { Minimum } \\
(\%)\end{array}$ & $\begin{array}{c}\text { Maximum } \\
(\%)\end{array}$ \\
\hline Hhohho & 71.0 & 27.1 & 91.8 \\
Manzini & 61.5 & 19.8 & 89.0 \\
Shiselweni & 62.3 & 23.9 & 87.4 \\
\hline
\end{tabular}

Table 10 is a summary of technical, allocative and economic efficiency of maize production in Swaziland. The results show that maize farmers in Swaziland are economically efficient in producing maize though there is more room for improvement. The overall mean economic efficiency was $64.3 \%$. Farmers can still reduce input costs by $35.7 \%$, while maintaining the same output, or they can increase output by $35.7 \%$ while still maintaining the same input costs and technology. The technical and economic efficiency scores showed some small differences between them. Allocative efficiency scores were very high as both the minimum and the maximum were above $99 \%$. We can therefore accept the alternative hypothesis, meaning that farmers are economically efficient. 
Table 10. Summary of efficiency scores

\begin{tabular}{lccc}
\hline Range & TE $(\%)$ & AE $(\%)$ & EE (\%) \\
\hline Average & 64.7 & 99.52 & 64.3 \\
Maximum & 92.1 & 99.53 & 91.6 \\
Minimum & 19.8 & 99.50 & 19.7 \\
\hline
\end{tabular}

4.5 Factors affecting technical, allocative and economic efficiency

\subsubsection{Technical efficiency}

Table 11 indicates that among the factors affecting technical efficiency, formal education was found to be positively related to technical efficiency and statistically significant $(\mathrm{P}<0.10)$. This means a one year increase in formal education increases technical efficiency by 0.0056 . On the other hand, the effect of household size was found to be negatively related to technical efficiency. An increase by one person in household size reduces technical efficiency by 0.0119. The coefficient was statistically significant $(\mathrm{P}<0.01)$.

The negative relationship is attributed to the fact that as the household size increases by one member, more resources are being channeled to maintaining the household instead of getting productive inputs. Essilfie (2011) got similar results and their argument was that large household size increases the population pressure on the farmer's limited resources due to the increased household spending and thereby reducing timely operations of farming activities.

\subsubsection{Allocative efficiency}

Table 11 shows that Famers who went through formal education were found to negatively affect allocative efficiency and their coefficient is statistically significant at $10 \%$ level. This could be caused by the fact that those who went through formal education some of them had other sources of income and were employed. This means that they are usually not available to ensure that the inputs they buy are used at optimal level. As expected, the household size negatively affects allocative efficiency and is statistically significant at 5\% level. Male farmers were found to be negatively related to efficiency and the coefficient is statistically significant at $5 \%$ level

\subsubsection{Economic efficiency}

The results in Table 11 show that the household size coefficient concurs with the a priori expectation. It is negative and statistically significant at $10 \%$ level. This means that a one person increase in household size would reduce economic efficiency by 0.0108 . This could be explained by the fact that once households get bigger, the money that could have been spent on inputs and technology is being diverted to family needs. Essilfie (2011) also had similar findings, and their argument was based on the fact that large household size increases the population pressure on the farmer's limited resources due to increases in household spending. 
Table 11. Tobit regression estimates of technical, allocative and economic efficiency

\begin{tabular}{|c|c|c|c|c|c|c|c|c|c|}
\hline \multirow[t]{2}{*}{ Factors } & \multicolumn{3}{|c|}{ Technical efficiency } & \multicolumn{3}{|c|}{ Allocative efficiency } & \multicolumn{3}{|c|}{ Economic efficiency } \\
\hline & Coef. & $\mathrm{t}$ & $\mathrm{p}$-value & Coef. & t-value & p-value & Coef. & $\mathrm{t}$ & P-value \\
\hline Farmer’s age (Yrs) & 0.0017 & 1.03 & 0.302 & 3.39E-07 & 0.80 & 0.426 & 0.0014 & 0.91 & 0.362 \\
\hline Farming experience (Yrs) & 0.0019 & 1.11 & 0.27 & $-1.24 \mathrm{E}-07$ & -0.27 & 0.786 & 0.0018 & 1.13 & 0.262 \\
\hline Formal education (Yrs) & $0.0056^{* * *}$ & 1.72 & 0.087 & $-1.4 \mathrm{E}-06 * * *$ & -1.70 & 0.09 & 0.0037 & 1.22 & 0.224 \\
\hline Gender (Male -1 , otherwise -0 ) & 0.0033 & 0.12 & 0.904 & $-0.00015^{* *}$ & -2.09 & 0.038 & 0.0006 & 0.02 & 0.981 \\
\hline Household size (Persons) & $-0.01109 *$ & -2.90 & 0.004 & $-2.59 \mathrm{E}-06^{* *}$ & -2.37 & 0.019 & $-0.0108 *$ & -2.81 & 0.005 \\
\hline Off-farm income (yes -1 , No-0) & -0.0267 & -0.87 & 0.384 & $-1.56 \mathrm{E}-06$ & -0.19 & 0.849 & -0.0150 & -0.52 & 0.602 \\
\hline Occupation (F/T farmer-1, otherwise-0) & -0.0323 & -1.03 & 0.303 & $-8.83 E-06$ & -1.06 & 0.29 & -0.0361 & -1.24 & 0.218 \\
\hline Cropping system (Mono-1, otherwise-0) & -0.0291 & -1.38 & 0.170 & $-2.82 \mathrm{E}-06$ & -0.50 & 0.617 & -0.0298 & -1.51 & 0.133 \\
\hline Seed type (Hybrid-1, otherwise -0) & 0.0029 & 0.18 & 0.860 & $4.78 \mathrm{E}-06$ & 1.09 & 0.275 & 0.0028 & 0.18 & 0.857 \\
\hline Constant & 0.5568 & 5.93 & 0.000 & 0.994101 & 39791.48 & 0.000 & 0.6168 & 7.03 & 0.000 \\
\hline
\end{tabular}

$*$ Significant at $1 \%$ level

**Significant at $5 \%$ level

$* * *$ Significant at $10 \%$ level

\section{Conclusions and Recommendations}

\subsection{Conclusions}

The results of the technical efficiency indicated that farm size was negatively related to output and the amount of fertilizer was positively related to output and were both significant at $1 \%$ level of significance. This implies that in order to increase maize output farmers need to improve productivity and increase the amount of fertilizer used per ha. Farmers are currently over-utilizing their inputs by $35.7 \%$. The amount of pesticide and labour should be increased. Farmers in Swaziland use inputs at minimum costs, this was indicated by the mean allocative efficiency of 99.52\%. In terms of economic efficiency, farmers can still reduce costs incurred and input used by $35.7 \%$. Since economic efficiency is a product of technical and allocative efficiency. Economic efficiency was affected by formal education, gender and household size. Based on the results of the analysis, the null hypotheses are rejected and the alternative hypotheses are accepted for both economic efficiency and for factors affecting economic efficiency in that, smallholder farmers were relatively economically efficient in producing maize in Swaziland and that there are factors affecting economic efficiency.

\subsection{Recommendations for maize farmers}

1. As population increases per year there is need to use available resources economically. Farmers can do that by applying the recommended rates of fertilizer and seeds per hectare. On the other hand, they need to increase the use of pesticide as it is currently under-used

2. Farmers should also make use of the services provided by extension officers so that they may be more economically efficient 


\subsection{Policy recommendations}

1. Farmers are not using inputs in the right proportion, therefore there is a need to increase the number of extension workers to train and educate farmers on the appropriate use of inputs.

2. There is need to subsidize inputs as farmers are spending less on inputs yet they are not highly productive

\section{References}

Bravo-ureta, B. E., \& Pinheiro, A. E. (1997). Technical, Economic, and Allocative Efficiency in Peasant Farming: Evidence from the Dominican Republic. The Developing Economies, 35(1), 48-67. http://dx.doi.org/10.1111/j.1746-1049.1997.tb01186.x

Chiona, S. (2011). Technical and allocative efficiency of smallholder maize farmers in Zambia. Master's Thesis, University of Zambia, Zambia

Chukwuji, C. O., Inoni, E.O. Ogisi, O.D., \& Oyaide, W. J. (2006). A Quantitative Determination of Allocative Efficiency in Broiler Production in Delta State, Nigeria. Agricultural Conspectus Scientificus, 71(1), (21-26).

Coelli, T. J. (1996). Specification and Estimation of Stochastic Frontier Production Functions. School of Economic Studies, University of New England, Armidale, Australia

Dlamini, D.D., \& Masuku, M.B. (2011). Land Tenure and Land Productivity: A Case of Maize Production in Swaziland. Asian Journal of Agricultural Sciences, 3(4), 301-307

Essilfie, L. E. (2011). Estimation of Farm level Technical Efficiency in Small Scale Maize Production in the Mfantseman Municipality in the Central Region of Ghana: A stochastic frontier approach. Journal of Development and Agricultural Economics, 3(14), 645-654.

Farell, J. M. (1957). Measurement of Productive Efficiency. Journal Royal Statistics, 120(3), 253-290. http://dx.doi.org/10.2307/2343100

Food Agriculture and Natural Resources Policy Analysis Network. (2003). Maize marketing Policy Strategy for Swaziland

Frisvold, G., \& Ingram, K. (1994). Sources of Agricultural Productivity Growth and Stagnation in Sub-Saharan Africa. Agricultural Economics, 13, 51-61. http://dx.doi.org/10.1016/0169-5150(95)01143-9

Khan, H., \& Saeed, I. (2011). Measurement of Technical, Allocative and Economic Efficiency of Tomato Farms in Northern Pakistan. International Conference on Management, Bangkok.

Magagula, S.D.M., Dlamini, E.V., \& Mkhwanazi, E.M. (2007). Modern Agriculture for 
Swaziland ( $2^{\text {nd }}$ ed). Oxford University, South Africa

Merwe, E.V. (2012). Economic Literacy as a Factor Affecting Allocative Efficiency. University of Free State, Department of Agricultural economics

Ministry of Agriculture. (2013). Agricultural services. Mbabane, Swaziland

National Maize Corporation (NMC). (2012). Annual Report, Matsapha, Swaziland

National Maize Corporation (NMC). (2013). Annual Report, Matsapha, Swaziland

Okoye, B.C., Onyenweaku, C.E., \& Asumugha, G.N. (2006). Allocative Efficiency of Small-Holder Cocoyam Farmers in Anambra State, Nigeria. Agricultural Journal, 4(38), 70-81.

Ozkan, B., Ceylan, R.F., \& Kizilay, H. (2009). A Review of Literature on Productive Efficiency in Agricultural Production. Journal of Applied Science Research, 5(7), 796-801.

Roberts-Lombard, M. (2006). Marketing research: a Southern African Perspective.

Russel, N.P., \& Young, T. (1983). Frontier production function and the measurement of technical efficiency. Journal of Agricultural Economics, 34(2), 139-150. http://dx.doi.org/10.1111/j.1477-9552.1983.tb00984.x

Sarafidis, V. (2002). An Assessment of Comparative Efficiency Measurement Techniques. Europe Economics, Occasional Paper 2, London.

Speelman, S., D’Haese, M., Buysse, J., \& D’Haese, L. (2008). A measure for the efficiency of water use and its determinants, a case study of small-scale irrigation schemes in North-West Province, South Africa. Agricultural Systems, 98(1), 31-39. http://dx.doi.org/10.1016/j.agsy.2008.03.006

West, W.H. (2000). On Africa Land Holdings: A Review of Tenurial Change and Land Policies in Anglophone Africa. Studies in African Economic and Social Development, $16,100-120$

Wu, C.C. (1979). Price-Output Uncertainty and Allocative Efficiency: An Empirical Study of Small-Scale Farms. The Review of Economics and Statistics, 61(2), 228-2. http://dx.doi.org/10.2307/1924590

\section{Copyright Disclaimer}

Copyright reserved by the author(s).

This article is an open-access article distributed under the terms and conditions of the Creative Commons Attribution license (http://creativecommons.org/licenses/by/3.0/). 